\title{
DE LA DESIGUALDAD PERSONAL EN LA SOCIEDAD CIVIL DE RAMÓN CAMPOS: UNA OBRA SINGULAR
}

\author{
Santiago LORENZO GARCÍA ${ }^{1}$
}

Universidad de Alicante

Se ha utilizado a menudo la expresión «ilustrados de segunda fila» para el caso español. Esta expresión ha escondido generalmente una inexplicable falta de interés por el estudio de algunos intelectuales del siglo XVIII hispano, que han pasado al olvido de forma inmerecida. Este artículo trata de la vida y obra de uno de esos ilustrados: Ramón Campos Pérez.

Autores como Cayctano Mas, Lucienne Domergue y Alain Guy ya han dado los primeros pasos en el análisis de sus escritos, aunque carecemos hasta la fecha de un estudio monográfico en profundidad acerca de su pensamiento ${ }^{2}$.

Campos nace en Burriana, provincia de Castellón, en torno a 1765. Los datos que poseemos acerca de su famila son escasos. Todo parece indicar que se trataría de una familia humilde, aunque su tío Don José Pérez, hermano de su madre, scrá un personaje de prestigio dentro del mundo de las letras. Pérez inició su cartera en la Universidad de Valencia, donde, entre los años 1744 y 1755 , será pieza clave en la introducción de la filosofía y la ciencia que se desarrollaba en esos momentos en Europa. Relacionado con el ideario reformista en materia de religión y con algunas de las posturas del llamado «jansenismo español», pasó en 1760, a Madrid, entrando en contacto con el grupo ilustrado de Pérez Bayer. Durante este periplo cortesano, Pérez se relacionó con personajes relevantes desde un punto de vista político e intelectual, lo que le valdría ser propuesto años más tarde para la dirección de los Reales Estudios de San Isidro. Tras tres expedientes inquisitoriales de los que salió indemne, D. José volvió a Valencia en 1767 , para pasar fïnalmente al Seminario de San Fulgencio de Murcia, donde ocupó el cargo de rector entre los años 1772 y 1780 . Allí José Pérez llevó a cabo una importante labor de reforma, confeccionando el nuevo Plan de Estudios de Filosofía y Teología que entró en vigor en el centro el 16 de septiembre de 1774. 
No es difícil suponer que su tío tendría un papel destacado en el ingreso de Campos en el Seminario murciano. Nuestro personaje dio comienzo con ello una vida dedicada por entero al estudio y las letras. Todo parece indicar que la carrera de D. Ramón se orientó en un principio hacia la Iglesia, pero la desaparición del archivo del Seminario nos impide conocer cualquier detalle acerca de este particular. Tampoco conocemos datos exactos acerca de su curriculum académico, aunque parece que su expedientc sería más que brillante. Así lo confirma el hecho de que fuese elegido, al linalizar el tercer año de teología, para defender públicamente las Conclusiones Procolegio que cada año debían llevar a cabo los mejores alumnos de tercero de teología. Campos estudió en el seminario un total de ocho años, tres de filosofía y cinco más de teología entre 1779 y 1782. Es lógico pensar que, a lo largo de ese periodo, su formación intelcctual se vería marcada por el clima reinante en el centro, un clima dominado por posturas muy próximas al ambiente ilustrado reformista. Finalmente, el ilustrado valenciano ocupó plaza docente en dicho centro. Es entonces cuando topó por vez primera con el Santo Oficio, como consecuencia de la denuncia de uno de sus discípulos en 1788, aunque la pesquisa inquisitorial no pasó a mayores. A partir de 1790 comenzó a realizar viajes a Madrid, optando ese mismo año a una cáledra vacante de física experimental en los Reales Estudios de San Isidro. No la consiguió, aunque sus frecuentes visitas a la capital del reino le permitieron entrar en contacto con el mundo cultural cortesano. En su segunda estancia en Madrid publicó su primera obra de importancia: Sistema de Lógica (1791), donde está muy presente el sensualismo de Condillac. En 1793 inició un viaje que le llevó a Inglaterra y Francia, con vistas a estudiar los avances técnicos de esos dos países, sobre todo en lo tocante a ingeniería hidraúlica y agricultura. Este periplo contaría a buen seguro con el apoyo del gobierno. Volvió a España en 1796, publicando un año después otro escrito: la Económica reducida a principios exactos, claros y sencillos, que resulta ser un compendio de las ideas del liberalismo económico de Adam Smith. En mayo de 1798, D. Ramón cayó en desgracia, siendo trasladado a la prisión del Castillo de San Lorenzo de Málaga. Parece que el encarcelamiento tendría más que ver con motivos de índole política que con cuestiones de ortodoxia religiosa, lo cual explicaría el que la orden de prisión fuese diclada por el mismo Rey. A lo largo de su encierro obligado, el ilustrado de Burriana ocupó su tiempo en dar forma a De la desigualdad personal en la sociedad civil (1799).

La elapa final de la vida de Campos presenta a sus biógrafos numerosos intcrogantes aún no esclarecidos. Únicamente sabemos que saldría de prisión hacia 1802 y que seguramente volvería a Madrid, donde habría vivido de lo producido por sus tareas literarias y donde publicó su última obra en 1804: El don de la palabra, en la que el sensualismo del Sistema de Lógica se encuentra más acentuado y mejor definido. Murió linalmente en Belmonte (Cuenca) en el año 1808, luchando contra la invasión napoleónica. Quedan en el aire, sin embargo, múltiples interrogantes: ¿qué poderosos enemigos tendría D. Ramón para dar con él en prisión?; ¿cuáles serían sus pasos después de salir de la cárcel?; ¿qué hay de cierto en las supuestas ideas de corte republicano que se 1legaron a atribuir a nuestro autor en 1808 ? Es esta última una cuestión apasionante, que, de confirmarse, otorgaría aún mayor valor a la figura de Campos. 
Como ya hemos visto a lo largo de la breve biografía que hemos expuesto anteriormente, la producción de Campos comprende cuatro obras mayores ${ }^{3}$. De entre ellas, la más sorprendente por su originalidad es De la desigualdad personal en la sociedad civil. En ella, su autor combina influencias que le llegan desde las ilustraciones francesa $\mathrm{e}$ inglesa con aportaciones personales. De Francia toma los presupuestos sensualistas de Condillac y Destutt de Tracy, y de Inglaterra recibe los novedosos principios de la física newtoniana, así como alguna de las idcas de David Hume y Adam Smith.

Antes de abordar un análisis de esta obra en particular es fundamental, en nuestra opinión, remitirse a las circunstancias que rodean la confección y postcrior publicación de este escrito.

La existencia de esta obra se certifica por primera vez en una carta dirigida por Ramón Campos al Rey con fecha de 26 de marzo de 1800. En ella el preso solicita una reducción de condena y da noticia de su escrito para conseguir que se le revise con vistas a una posterior publicación:

«...tratando de imprimirlo ahora, necesitando por razón de su originalidad confcceionarlo de antemano con los literatos de la Corte; cuya diligencia no puede practicarse si no es personalmenie»4.

La súplica fue, por supuesto, desatendida y en nota marginal se recomendaba al cncarcelado que dejase las tareas literarias para mejor ocasión: «dígasele que no convienen obras que den lugar a tales disputas, y que dexe esto».

El 30 de abril D. Ramón reiteraba la petición con idéntica poca fortuna, de manera que decidió dirigirse al Secretario de Estado, D. Mariano Luis de Urquijo, en carta de 24 de mayo. En ella Campos ofrece nuevas referencias sobre su obra recién terminada:

«...cl libro del qual se me acaba de reconvenir de parte de V. E. no lo compuse con la mira de imprimirlo sino puramente con la de recopilar y de tener guardadas mis ocurrencias en un tiempo en que la absoluta falta de libertad no me permitía otra ocupación: $Y$ el pensamiento de pedir por vía de $\mathrm{V}$. E. la licencia de imprimirlo con las rectificaciones que yo iba a hacer, y con las de quienes más sufriesen, sugctándolo antes ciegamente a la corrección de censores, ha sido posterior. Intentando con cllo hacer mérito para cl logro de la libertad de que carezco quatro años hace (...).

Aí está el libro a la disposición o a la enmienda de $V$. E. igualmente que acá mi persona y mis facultades. Envióselo a V. E. qual lo tenía preparado con sus grandes claros para que cupiesen las enmiendas que en mi dietamen requería. Nadie mejor que $\mathrm{V}$. E. puede ser juez del contenido» 5 .

Urquijo tampoco atenderá las razones expuestas por Campos, formándose además juicios poco favorables en relación a De la desigualdad...: «la obra vale poco, y si así no fuerc, no pudiera ni aun soñar en escribir de tales materias. Tiene además mucho de plagio, y de esto no debe tratarse directa ni indirectamente». La obra pasó sin más al archivo de la Secretaría.

Desde su destierro obligado, el ilustrado de Burriana aún tendría ánimos para realizar una última llamada a Urquijo. En ella se hacía alusión a las diferentes ideas 
expresadas en el escrito para intentar echar por tierra las posibles calumnias que acerca de él se estarían esparciendo con toda probabilidad en círculos cortesanos: «...como confío, el concepto que los dos enemigos míos han procurado esparcir de mí, representándome como un hombre ocioso y jacobino [...] ...se sirva hacer alto en el capítulo de la decadencia de la ingenuidad para graduar el fundamento de la nota que ha traslucido se me ha puesto de no ser cauto en el hablar».

El Secretario de Estado volvió a desoír los argumentos de nuestro autor, debiendo cumplir Campos su pena hasta el último día y no consiguiendo ver su obra publicada ni siquiera tras salir de la cárcel en el año 1802. El 2 de julio de 1804 solicitaba de la Secretaría la devolución del manuscrito original de su escrito, obteniéndolo sin excesiva dificultad el día 11 del mismo mes. En 1808, fecha de su fallecimiento, Ramón Campos no había podido ver todavía su obra impresa en letras de molde. Tendrían que pasar algunos años más para que esto sucediese. De la desigualdad personal en la sociedad civil fue finalmente publicada por vez primera en París en 1823; en España no vería la luz hasta fecha tan tardía como 1838, en Barcelona.

Un dato que hemos de tener bien presente es que el libro sería redactado a to largo del año 1799, cumpliendo Campos condena. Crcemos que ello inlluiría decisivamente en algunos de los planteamientos que aparecen en el texto. Ciertamente, una primera lectura nos puede dar la impresión de que De la desigualdad... podría ser entendida como una obra que justifica el ordenamiento social en el que se ve inmerso Campos, aunque más adelante veremos que tal idea ha de ser muy matizada. En este ordenamiento social las desigualdades son necesarias y forman parte fundamental del plan de la naturaleza para perfeccionar nuestra especie. Las desigualdades sociales son motor del avance social en todos los terrenos (político, económico, cultural,etc.); son motor, en suma, del progreso de la civilización. Es un pensamiento que ya queda perfectamente claro desde lo expuesto por el filósofo de Burriana en la introducción de su libro:

«En todos los tiempos se ha hecho mérito de la cultura del entendimiento, y en el más culto de ellos necesila de apología. No parece sino que, de puro cultos, ya lastidia el serlo. Del salvaje al ciudadano hubo siempre una distancia casi infinita, y ahora se pretende que no hay siquiera un paso, y que los miles de años que cuesta la civilización son un trabajo cnteramente inútil. Tal suena la igualdad entre las heces de los bárbaros de África, y la flor de los cultos de la Europa; entre los negros y los esclavos de las colonias, y la gente fina de las naciones madres. Tal es también la opinión que cunde. Inténtase probar en el siguiente escrito que desde el salvaje hasta el hombre cullo, desde el mendigo hasta el magnate, hay una gradación progresiva de moralidad y racionalidad, de suerte que la dignidad y el valor intrínseco del individuo no es uno mismo en estas distintas clases. Y las distinciones políticas correspondientes a las diferencias naturales de cuna, haberes, sexo y oficio son la máquina que la naturaleza emplea para mejorar la especie»n.

Esta postura se opone abiertamente a las tesis de J. J. Rousseau, quien defiende la mayor felicidad y pureza que se asocia al estado primitivo de naluraleza, fren- 
te a la corrupción que trae aparejada el progreso y la civilización, y cuyo principal alegato lo encontramos en su escrito Discurso sobre el origen y fundamentos de la desigualdad entre los hombres. Allí el intelectual ginebrino defiende que el hombre era plenamente feliz en ese estado primitivo de naturaleza, donde no existía el egoísmo, ni los odios, ni las luchas, pues la naturaleza se encargaba generosamente de ofrecer todo lo que debía satisfacer sus necesidades. Encontramos en estas ideas el germen de la leyenda del buen salvaje, que comienza a tomar cuerpo con Rousseau, teniendo gran éxito más adelante en algunos escritores románticos del XIX como Chateaubriand. Pero ese estado inicial de felicidad se pierde, para Rousseau, con la formación de grandes núcleos sociales, con la aparición de la agricultura y de la propiedad privada, todo lo cual engendró la envidia, la ambición, el odio y la guerra; la desigualdad social, en definitiva. La vía de solución a este cstado de corrupción viene por la vuelta a la vida natural y el rechazo a la sociedad y civilización que la destruyó.

Es evidente que Campos no comparte, pese a la similitud existente entre los títulos de las obras de ambos escritores, tales planteamientos. Al contrario, se puede decir que se sitúa en posiciones deliberada y claramente opuestas. El ilustrado valenciano contempla como positivo, como ya ha quedado dicho, el progreso de la civilización. Pero el punto que ha levantado ampollas entre los analistas de las ideas de Campos es el que se refiere a cómo trata éste las desigualdades sociales. Las concibe D. Ramón como algo que se encuentra en el plan de la naturaleza para perfeccionar la especie. Este pensamiento ha hecho que algunos de los autores que han estudiado su obra lo hayan catalogado como un intelectual reaccionario y defensor de la sociedad estamental de su tiempo. Es el caso de Antonio Elorza, quien adscribe al autor de Burriana al grupo menos progresista de la Ilustración española:

«En realidad Campos no es sino un pensador que expresa y defiende congruentemente la estructura social en que se halla inserto. [...] Campos siempre acepta las escalas de prestigio preestablecidas: la riqueza adquirida por sí mismo no tiene a sus ojos el mismo valor que la que se deriva de una renta. Es, pues, el suyo un intento nada generoso de justificar el anquilosamiento finisccular de la España de Carlos IV. La sociedad estamental, de cuya desigualdad han pasado a disfrutar algunos grupos burgueses, es justa porque se apoya en unas diferencias que responden al distinto valor de los individuos que desempeñan sus diversas funciones...»?

Nos parece que hace más justicia a los contenidos vertidos en De la desigualdad personal en la sociedad civil el parecer de Alain Guy sobre este particular. En su análisis sobre Ramón Campos resalta, frente al supuesto conservadurismo do Campos, su perfil más puramente moderno, progresista e ilustrado: «Campos semble esquisser une conclusion, dont le sens ambigu m'apparaît toutefois, dans son expression enveloppée, comme authentiquement progressiste pour son époque et pour son pays»8. Sirva como bolón de muestra a este respecto una cita extraída del escrito de Campos en la que éste se muestra crítico con los privilegios de la nobleza de su tiem- 
po. En ella D. Ramón otorga mayor valor a los comportamientos sociales que a la alcurnia, participando con ello del carácter reformista que define a la Ilustración española:

«Pero no sea esto ocasión para que la nobleza moderna se engría de sus ridículos privilegios, y de sus pergaminos y protocolos todavía más ridículos, rezando unos parentescos con Wamba, otros con Galba, y quienes subiendo la alcurnia hasta Noé. En mil años de sucesión, malo será le falte a nadie un ascendiente que se haya señalado en mérito y otro en villanía.

Los ilustres parientes que miramos como estímulo, o que tienen opción al agradecimiento del público, no son los remotos del tiempo del diluvio, o del tiempo de los Moros, cuyos beneficios o hazañas ya ni agradecemos ni admiramos, sino los parientes inmediatos, aquéllos cuyo rostro esté todavía en la memoria de las gentes, cuyos beneficios se estén reconociendo y palpando aún, y cuyas máximas y ejemplo haya verosimilitud de conservarse aún en la familia»".

En este sentido, Guy hace hincapié en que el tono moderado de algunos de los pensamientos del intelectual español viene dado por su posición deslavorable en unos momentos en que desea salir de presidio moviendo los cables más a propósito para este fin. Advierte Guy asimismo que al final del libro Campos realiza una importante advertencia que no podemos pasar por alto y es que, más que crílico o defensor de la sociedad de su tiempo, éste se declara un mero analista de la realidad. Ramón Campos no sería, pues, un defensor a ultranza de la sociedad estamental del momento; podríamos concluir más bien que lo que está pretendiendo nuestro autor es un estudio, una descripción, como observador desde fuera, de la realidad social en la que se inscribe. Esto es, pretende dar constancia de lo que hay y de por qué existe, no enjuiciar una situación. Cuando profundicemos más adelante en este apartado al analizar el pensamiento filosófico y político de Campos, veremos que su propósito es analizar con un método riguroso, el científico, y no echar por lierra o ensalzar las desigualdades sociales que, queramos o no, son un instrumento en manos de la naturaleza para alcanzar la mejora de la humanidad y contra el que nosotros, por mucho que nos empeñemos, no podemos luchar:

«Y no importa, ni nos entretenemos aquí en aprobar o criticar las desigualdades particulares solemnizadas o abolidas en ningún país. Debiéndose entender que lo que se ha censurado de algunos usos, unas veces nacionales y otras extranjeros, no ha sido con ánimo de remorderlos o de dar un voto inoportuno, sino tan sólo con cl de desentrañar la significación y esencia de las desigualdades facticias que han sido el objeto de este capítulo y de todo el libro» 10 .

Uno de los rasgos que otorga originalidad a esta obra es la diversidad de temas que D. Ramón aborda en sus páginas. Uno de ellos es la economía, a la que, con anterioridad, nuestro autor ya había dedicado un estudio monográfico: la Económica reducida a principios exactos, claros y sencillos (1797), con el que había pretendido elcvar esta disciplina a la categoría de las ciencias exactas. En De la desigualdad personal en la sociedad civil la economía es vista siguiendo los presupuestos ya explicados en su prólogo. Así, es la naturaleza a través de unas leyes la que organiza la vida material de los hom- 
bres, valiéndose para ello de las desigualdades económicas, de modo que son esas desigualdades las que empujan la creación de riquezas en una nación:

«El no causar gran lástima la pobreza consiste en que la reparemos poco, en que no nos informamos bien del equipaje, de la hediondez y de la miseria, en que la imaginación no coge pie para pintarse con viveza la escualidez del pobre.

Si la pobreza causasc una compasión seria, cual causaría reparándola mucho, todos partiríamos con el pobre el pan: no hubiera pobre ninguno ni interés en no serlo. El trabajo o aplicación decayera sin límite, y la sociedad perdiera el estímulo cconómico. El no mirar, pues, al pobre, es el móvil económico de la sociedad.

También si la riqueza no causase la distinción que le tributamos, lo mismo nos importaría ropa buena que ropa mala, ir de moda que a la antigua, medio vestidos que del todo, cl palacio que la choza, el desaliño que el aseo. Serían inútiles las riquezas, y nadie gastaría su calor en acopiarlas.

No habiendo caudales acopiados, sería absolutamente imposible la subdivisión de oficios, cada hombre los reuniría en sí todos, y la sociedad no podría salir del cstado salvaje.

La civilización, pucs, procede evidentemente de la mayor suposición del rico. Y la distinción de las riquezas es un registro o instinto absolutamente esencial en cl plan de la culturas"!

La cuestión religiosa ocupa, por su parte, un lugar muy pequeño dentro de las cuatro obras mayores de Campos. Teniendo esto presente, estamos con Cayctano Mas cuando apunta que «no podemos pretender remontarnos a efectuar una valoración delinitiva y profunda de las posiciones del autor en materia de religión. Esto no es posible ni tan siquiera a partir del conjunto de su obra publicada en el periodo de madurez>> ${ }^{12}$. Las escasas ideas que se refieren a la religión se encuentran en un capítulo de De la desigualdad personal... que se titula: «Del efecto de la solemnización del traje en los clérigos y religiosos». Es la única vez, dentro de sus escritos, en la que nuestro autor se decide a tocar de forma directa la institución eclesiástica. Pese a que Campos cscribe csta obra en la cárcel y mantiene siempre extremado cuidado en lo que dice y cómo lo dice, éste no puede evitar lanzar alguna que otra crílica a la relajación de los ministros de la Iglesia, que han fomentado la exteriorización del culto en perjuicio de una religiosidad más pura e intimista. Según su punto de vista, se descuida, en suma, la verdadera esencia de la religión al primarse aspectos superficiales como el uniforme de los clérigos ("Puede decirse en algún modo que ya cl hábito hace al monje"), la jerga eclesiástica y las ceremonias y ritos:

«La solemnización, pues, de idioma y de traje distinto, a pesar de tener un excelente origen y de convenir para otros fines, tiene tendencia de relajar gradualmente tanto los ministros como sus leligreses» 13 .

Las críticas amainan cuando se trata del clero secular al que cl filósofo valenciano mira con mejores ojos que a los regulares, situándolos en un nivel religioso y cultural superior.

El interés reformista también está presente en esta cuestión. Ramón Campos participa de la preocupación existente entre los ilustrados cspañoles por el grado de 
degradación espiritual al que está llegando la institución eclesiástica. Es necesario que se realice una reforma que revalorice lo espiritual del credo frente a lo meramente superficial:

«... se irá relajando más el misterio de la religión y su fervor en los creyentes, a no ser que se haga alguna reforma, o que Dios por su alto poderío, sostenga a unos y otros milagrosamente» 14 .

Estos presupuestos reformadores acercan al intelectual valenciano a algunas posturas jansenistas, que van a tener éxito en la España de la segunda mitad del XVIII. No podemos olvidar, en este sentido, que fue en el Seminario de San Fulgencio de Murcia donde D. Ramón se formó académicamente, y que dicho centro se convirtió en uno de los focos más destacados del reformismo religioso de la llustración, lo que no podía dejar de influir en las ideas de nuestro autor.

Pero tenemos que tener presente que si por algo se caracteriza De la desigualdad personal en la sociedad civil es por pretender ser un tratado político ${ }^{15}$, entendiendo este último término como todo aquello que se refiere a la convivencia en sociedad de los hombres ${ }^{16}$. Una convivencia que es vista como necesaria, pues el ilustrado valenciano concibe la sociedad como algo innato al hombre. Es algo que nace con él y que deriva de dos flujos naturales o instintos que la naturaleza ha sellado en el espíritu humano: el «flujo porque nos hagan caso», por llamar la atención de los demás y ser centro de las miradas de los otros, y el «flujo por armonizar», esto es, por casar con el resto, por no salirse de las reglas establecidas que siguen los demás integrantes de la comunidad:

«Si el flujo por no disonar de los demás es el instrumento de la moralización del hombre, también el flujo por tener a quien esté a nuestro igual, el flujo porque nuestros movimientos interiores tengan correspondencia en el corazón de los demás, es el móvil que nos impele a la sociedad, que, nacidos ya en ella, nos la hace mirar como cl elemento de la vida. De suerte que la sociedad política no es efecto de ningún contrato expreso ni tácito, sino una erupción espontánea e indeliberada, procedida únicamente de la propensión natural a la compañía con nuestros semejantes [...]. El llujo por armonizar con los de nuestra especie, y el flujo porque nos hagan caso subordinan el individuo a la comunidad. Y esta sola ojeada es suficiente para comprender que en la organización del hombre la naturaleza no intentó formar un ente aislado, independiente, inconexo, desprendido de los demás, y bastante a solas para sí, sino un dependiente de familia, un miembro de cuerpo, una parte de un todo mayor» 17.

Sigue, por tanto, Campos ideas como las de Hume, para quien la sociedad es algo consustancial al hombre, negando de forma explícita la posibilidad de un contrato social original como puente entre un estado de naturaleza primitivo y la sociedad ya plenamente constituida: «El hombre, nacido en el seno de una familia, ha de mantener la vida social por necesidad, inclinación natural y hábito»18). Y estos no son los únicos presupuestos que el ilustrado de Burriana toma de la escuela escoce- 
sa, y más concretamente de David Hume. De este último toma igualmente el peso que otorga al hábito o constumbre -frente a la razón- a la hora de definir el comportamiento humano en sociedad; un comportamiento que se refiere a las cuestiones de hecho por oposición a las cuestiones de derecho. De ellas, las primeras -las cuestiones de hecho- existen gracias a las leyes de la naturaleza y a sus designios ocultos para procurar el perfeccionamiento progresivo de la especic, mientras que las segundas se hallan incluidas en el terreno de la razón. Campos, por consiguiente, se ocupa en De la desigualdad personal en la sociedad civil de las cuestiones de hecho, de aquellas que se refieren a la conducta social y que conforman en un sentido amplio las relaciones políticas, dejando al margen las cuestiones de derecho, esto es, de la moral propiamente, de lo que debería ser; pues, como ya hemos dicho, Campos en esta obra no pretende ser juez, sino más bien espejo de la realidad social y política que contempla. Quiere Ilegar a las entrañas de esta realidad, analizándola. Para ello, ha de contar con un método a propósito para esta tarea, que no es otro que el nuevo método científico newtoniano, que tan buenos resultados había dado en su momento en el campo de la física. Un método que será tomado como punto de referencia básico una y otra vez por multitud de filósofos e ilustrados del siglo XVIII. Es el caso de David Hume, como bien ha apuntado J. M. Colomer en su estudio preliminar a los Ensayos Políticos del autor escocés: «...los conceptos o ideas complejas se forman a partir de ideas simples basadas en la experiencia sensible, mediante asociaciones de ideas (por semejanza, contigüidad, relaciones causales provocadas por la experiencia, etc.). Esta psicología asociacionista encuentra su analogía en el principio físico de la atracción universal de Newton y se apoya en la consideración de que la mente humana forma parte de la Naturaleza...»19.

En Philosophiae naturalis principia mathematica (1687), Newton presenta la teoría de la gravitación universal según la cual los cuerpos celestes se atraen en razón directa de sus masas y en razón inversa del cuadrado de sus distancias. Aporta con ello una solución definitiva al problema del movimiento de los astros, que termina de resolverse con la introducción del «principio de inercia» (todo cuerpo conserva su estado de reposo o movimiento rectilíneo uniforme hasta que un agente cxterior actúe sobre él y le obligue a cambiar de estado). Y gracias a la Lcy de gravitación universal se puede dar una explicación sólida no sólo al movimiento de los cuerpos celestes, sino también a la razón de ser de las órbitas elípticas de los planetas, al fenómeno de las mareas, a los movimientos de la luna en relación a la Tierra, etc.. Así, Newton destierra de forma definitiva el sistema del mundo físico propuesto por Aristótcles basado en el geocentrismo, en la dualidad del mundo físico (cuerpos terrestres corruptibles formados por los cuatro elementos y cuerpos celestes incorruptibles), y en la teoría de los movimientos naturales. Los esfucrzos científicos anteriores de Galileo y Copérnico quedaban recompensados.

Pero lo más importante de las aportaciones del científico inglés es la acuñación de un método de trabajo ciertamente revolucionario:

«Mas, al contemplar los Principia desde nuestra posición privilegiada de tres siglos después, me parece (como creo que les pareció a algunos newtonianos de la 
época de Newton) que lo más importante del magnífico libro de Newton no residía en los éxitos individuales ni en los nuevos métodos y conceptos exhibidos, ni incluso en el conjunto de las innovaciones newtonianas, sino más bien en el estilo newtoniano que los hizo posibles. En mi opinión, el aspecto más revolucionario de los Principia de Newton fue la elaboración de un método increíblemente eficaz para abordar matemáticamente las realidades del mundo externo, tal y como se muestran en los experimentos y observaciones y se codifican mediante la razón. A eso es a lo que yo llamo estilo newtoniano, el estilo adoptado en los Principia de Newion en aras del desarrollo de los principios matemáticos susceptibles de aplicarse de manera significativa y fecunda a la filosofía natural»20.

Ramón Campos utilizó el método de análisis newtoniano, pero no en el terreno de la física, sino en el campo social. El filósofo valenciano pretende hacer ver con su estudio que, igual que existen unas leyes físicas que rigen el mundo natural, existen unas leyes sociales que guían el comportamiento humano en comunidad. Son leyes sabias, que, aunque se escapen muchas veces al entendimiento humano, tienen como última finalidad conseguir en un proceso progresivo el bien común de la especie a través de los avances de la civilización y de la cultura en todos los terrenos, (política, sociedad, economía, etc.). Y así como Newton desveló las f́cyes físicas que rigen el comportamiento de los astros, dando a las mismas un soporte matemático, Campos se plantea la tarea de poner su grano de arena en la tentativa por hacer lo mismo en el campo de la política y la sociedad:

«Pues, como todos los entes tienen naturalmente las afinidades o tendencias, en virtud de las cuales sigue cada uno su carrera o su destino, así también, como se dijo al principio, el hombre tiene sus tendencias naturales, que independientemente del discurso, y aun contra los dictados del discurso, le hacen guardar esta vida o forma particular que llamamos racionalidad. Así, el flujo porque nos hagan caso, y el flujo por no estar al revés de los demás, son evidentemente los principios cardinales de la asociación y moralización. Aquellos dos flujos son unos movimientos o tendencias ciegas e indeliberadas del corazón, sin tener por cierto la más mínima conexión o roce con el discurso. Y lo mismo sucede en los demás flujos o propensiones generales, de suerte que en el sistema práctico de la racionalidad no es móvil en manera alguna el discurso.

Lo que se llama luz de la razón es una cosa muy distinta de la naturaleza. Ésta, en nosotros es un conjunto de afinidades o propensiones, o instintos. Y lá luz de la razón es una como antorcha que alumbra el interior. La naturaleza en nosotros obra imprimiéndonos un sistema de potencias o movimientos. Y la luz de la razón no tiene otro efecto si no es ver o calcular. Si los planetas tuvieran la luz de la razón, con ella podrían tal vez ajustar la cuenta de sus propios movimientos, pero no podrían trocar la dirección o intensidad de sus potencias. Podrían conocer que de este modo o del otro irían mejor o peor, pero este conocimiento, erróneo o fundado, no les crearía o aniquilaría las potencias o afinidades que les están impresas naturalmente.

Del mismo modo, aunque el ojo del discurso o la luz de la razón nos haga conocer o calcular nuestras tendencias o propensiones naturales; aunque, lanzándose, por decirlo así, fuera de nosotros, tantee el mundo y pronuncie las correcciones que se podrían o deberían hacer a nuestra naturaleza, no por eso produce o aniquila las tendencias del 
corazón, ni puede tener en nuestros movimientos naturales más influjo que los cálculos astronómicos en el movimiento de los planetas.

Así es que aunque el discurso diga que lo mismo es estar al revés que al derecho, la naturaleza nos hace desazonar de hallarnos al revés de los demás. También aunque diga que lo mismo nos debe ser hacer ruido que estar desconocidos, nos alegra irremediablemente el ver que se haga asunto de nosotros» 21 .

Campos asimila la sociedad a un enorme sistema planetario organizado matemáticamente. El principio de la gravitación universal, descubierto por Newton, tiene también cabida en lo social. Es esta inclinación natural la que une a los individuos en sociedad. Relaciona el intelectual de Burriana el Principio de «gravitación armónica» con las desigualdades argumentando que, de igual manera que los cuerpos físicos poseen diferente masa y, en consecuencia, atraen con mayor o menor fuerza a los restantes cuerpos físicos de su sistema, así los seres humanos que viven en comunidad son diferentes por naturaleza y atraen con mayor o menor poder a sus vecinos.

D. Ramón defiende, según todo lo expuesto hasta aquí, que la naturaleza humana responde a unas reglas eternas e invariables que procuran a la larga el bien del conjunto de todos los hombres, pese a que los comportamientos sociales puntuales puedan desorientarnos a primera vista. Nuestro autor usa el sensualismo para completar este argumento, recurriendo a sus maestros Condillac y Destutt de Tracy. El medio material que emplea la naturaleza para hacer cumplir sus designios en la práctica es la presencia de los otros o, más concretamente, la mirada de los demás. El cuerpo social se convierte, por tanto, en inspirador y juez de nuestra conducta.

Encontramos en todas estas ideas uno de los aspectos más originales de De la desigualdad personal en la sociedad civil, pues Campos está plantando los cimientos de una ciencia social del comportamiento. Esta ciencia de lo social podría ser asimilable a una sociología embrionaria22, ciertamente de perfiles algo confusos y aún no bien definidos; pero hemos de tener muy en cuenta, en este punto, la temprana época en la que se escribe esta obra. Es éste un apartado, en cualquier caso, interesante, que abre nuevas puertas a las investigaciones futuras. 


\section{NOTAS}

1.- Este artículo es un extracto de la Memoria de Licenciatura Ramón Campos, vida y obra de un ilustrado valenciano, dirigida por el Dr. Cayetano Mas y presentada por su autor el 20 de diciembre de 1994 en la Universidad de Alicante, obteniendo la calificación de sobresaliente cum laude.

2.- Una mayor información acerca de la vida y obra de Ramón Campos se halla contenicia en los estudios de Cayetano Mas, Ramón Campos Pérez. Philosophe el fois dans l'Espagne des Lumières, Universidad de Provenza, 1988; Alain Guy, «Ramón Campos, disciple de Condillac», en Pensée Hispanique et philosophie française des Lumières, Toulouse, 1980; Lucienne Domergue, «Ramón Campos ou les tribulations d'un philosophe espagnol des Lumières», Philosophie (XII-XIII-XIV), Université de Toulouse-le-Mirail, 1988, Tomo I; así como en la Memoria de Licenciatura Ramón Campos, vida y obra de tan ilusirado valenciano, del mismo autor de este artículo.

3.- Sistema de Lógica, Imprenta de la viuda de Ibarra, Madrid, 1791 (B. N., Madrid, 2/29. 201); la Económica reducida a principios exactos, claros y sencillos, Benito Cano, Madrid, 1797 (B. N., Madrid, 3/38.756); El don de la palabra, Gómcz Fuentenebro, Madrid, 1804 (B. N., Madrid, 1/3.967); y De la desigualdad personal en la sociedad civil, $2^{a}$ edición de Manuel Saurí, Barcelona, 1838 (B. N., Madrid, 1/13.457).

4.- A. H. N., Estado, exp. 8.

5.- A. H. N., Estado, leg. 3014-8, carta de Campos a Urquijo (Málaga, 24 de mayo de 1800).

6.- R. Campos, De la desiguladad personal en la sociedad civil, Instituto Juan Gil-Albert, Alicante, 1989, p. 59.

7.- A. Elorza, «Liberalismo económico y sociedad estamental a fines del siglo XVIII», en Moneda y Crédito, Revista de Economía, 110, Madrid, Septicmbre, 1969, p. 110.

8.- A. Guy, «Ramón Campos, disciple de Condillac», en Pensée Hispanique et Philosophie Française des Lumières, Université de Toulouse-Le-Mirail, Tome 45, 1980, p. 48.

9.- R. Campos, Op. cit.,p. 107.

10.- Ibidem, p. 185.

11.- Ibidem, p. 105.

12.- C. Mas, «Introducción» a De la desiguladad personal en la sociedad civil de R. Campos, Juan Gil-Albert, Alicante, 1989, p. 30.

13.- R. Campos, Op. cit., p. 117.

14.- Ibidem, pp. $117-118$.

15.- «En este libro no se habrá hecho poco, si se ha acertado a abrir el hasta aquí desconocido (mundo) de la política, y sentado los verdaderos preliminares para que puedan avenirse los que Io intenten de buena fe», en R. Campos, De la desigualdad..., p. 185.

16. - Cayetano Mas ha sabido explicar perfectamente cuál es el concepto de política que Campos concibe en De la desigualdad...: «Campos pretenderá sentar los "verdaderos preliminares" (cap. XIV) de la política, entendiéndola no en el sentido restrictivo actual, sino más ampliamente como "las reglas a ciencia" que rigen en "el trato entre rey y vasallos, entre un soberano y otro, entre nación y nación; entre un cuerpo y otro, y entre una clase y otra (...) sujeto a los mismos principios que el trato mutuo y particular de las personas". La plasmación de este planteamiento en la obra es -con lo que de rechazo se eliminan las 
cuestiones difíciles- centrarse en la esfera del comportamiento social y en las reglas que lo regulan, y no en la del poder, su organización y gestión». En «Introducción» de C. Mas a De la desigualdad..., Juan Gil-Albert, Alicante, 1989, p. 43.

17.- R. Campos, Op. cit., p. 69.

18.- D. Hume, Ensayos políticos, Tecnos, Madrid, 1987, p. 26.

19.- J. M. Colomer, «Estudio preliminar» a Ensayos politicos de D. Hume, Tecnos, Madrid, 1987, p. XVI.

20.- B. Cohen, La revolución newtoniana y la transformación de las ideas científicas, Alianza Universidad, Madrid, 1983, p. 70.

21.- R. Campos, Op. cit., pp. 97-98.

22.- Tengamos presente, en este sentido, que Comte, considerado el padre de la sociología, concebía a ésta como una física social, planteamiento que, a falta de ser explicado con un mayor delenimiento, indudablemente se acerca al análisis social y político que realiza nuestro autor como estamos intentando reflejar. 